\title{
ReFlexões ACERCA da Definição Estética DE ARTE DE MONROE BEARDSLEY ${ }^{1}$
}

Rosi Leny Morokawa ${ }^{2}$

(UFRJ, Brasil)

\section{Introdução}

Em "An Aesthetic Definition of Art" (1983), um de seus últimos textos, Monroe Beardsley apresentou uma definição de arte que, entre suas repercussões, trouxe ao centro da discussão em estética a noção de experiência estética no fazer artístico e em sua recepção. Sua definição de arte contrapõese a outras surgidas a partir de meados do século XX, como as de Arthur Danto (1964, 1981) e George Dickie (1974, 1984), que pertencem a teorias que são críticas de definições estéticas de arte.

Beardsley busca construir uma definição que trace uma distinção entre arte e não arte. Seu ponto de partida é que nas mais variadas sociedades humanas podemos identificar atividades artísticas que se relacionam com a produção e a recepção de obras de arte. Na produção de obras, está presente uma intenção do artista em produzir algo que possua a capacidade de proporcionar uma experiência estética. Na recepção de obras de arte, geralmente há a busca por obter uma experiência estética. Ele propõe, então, a seguinte definição de arte: "[u]ma obra de arte é algo produzido com a intenção de conferirlhe a capacidade de satisfazer o interesse estético" (1983: 58).

1 Este artigo foi escrito em parte durante pesquisa realizada com financiamento da CAPES.

2 Doutoranda em Filosofia no PPGLM da Universidade Federal do Rio de Janeiro UFRJ, Brasil. rosimorokawa@gmail.com

Philosophica, 53, Lisboa, 2019, pp. 125-140. 
Apesar de Beardsley propor uma condição estética que algo deva satisfazer para ser arte, ele não propõe essa definição estética em termos de propriedades estéticas intrínsecas ao objeto de arte. A condição estética que deve ser satisfeita para algo ser arte, de acordo com Beardsley, é a intenção de que algo possua a capacidade de proporcionar experiências estéticas. ${ }^{3}$ Sua definição, assim como as de Danto e Dickie, pode ser considerada uma definição relacional, de acordo com Kathleen Stock (2010). Beardsley define arte a partir da relação que obras de arte possuem com a função que desempenham na sociedade e, no caso da definição estética de arte, esta função é a de proporcionar experiências estéticas. A definição estética também é classificada por alguns filósofos como uma definição funcionalista da arte. ${ }^{4}$

Noël Carroll $(1999,2001)$ critica as definições estéticas de arte porque elas deixariam de fora grande parte da arte contemporânea - obras como, por exemplo, a Fonte de Marcel Duchamp. ${ }^{5}$ Essas obras, segundo Carroll, não foram feitas com a intenção de proporcionar experiências estéticas e algumas podem também não possuir a capacidade de proporcionálas. Além disso, Carroll argumenta que existem obras, como a Fonte de Duchamp, cujo estatuto de arte é anterior à apreciação delas como obras de arte.

Neste artigo, pretendo (1) apresentar a definição estética proposta por Beardsley, (2) mostrar o desafio que algumas formas de arte do século XX oferecem às definições estéticas de arte, segundo as objeções de Carroll; e (3) analisar como a definição estética de Beardsley pode responder àquele desafio.

\section{A definição estética de arte}

Quando queremos saber o que algo é, de modo geral, estamos perguntando sobre sua natureza, sobre aquilo que faz algo ser o que é e

3 Cabe aqui notar que Beardsley é o autor, juntamente com William K. Wimsatt, de um célebre artigo intitulado “A Falácia Intencional” (1949). Neste artigo, a expressão “falácia intencional" é utilizada para se referir ao engano de se atribuir uma dependência das intenções do autor ao significado e ao valor artístico da obra literária. Para Beardsley (1983), a proposta de que as intenções do artista não determinam a interpretação da obra é compatível com a proposta de que a intenção estética é necessária para criar uma obra de arte.

4 Cf. Stephen Davies (1991).

5 O artista francês Marcel Duchamp inscreveu no Salão dos Independentes de Nova Iorque de 1917, do qual fazia parte do júri, um urinol invertido que intitulou de "Fonte" e assinou como "R. Mutt". 
o distingue de outras coisas. A questão "O que é arte?", de um ponto de vista metafísico, requer uma resposta sobre a natureza ou essência da arte. Esta mesma questão também pode ser respondida de um ponto de vista semântico, quando o que se quer saber é o significado do termo "arte". Beardsley (1983: 55) propõe que é possível encontrar características comuns presentes em todas as obras artes, ou ao menos nas obras de artes consideradas como exemplos reconhecidos de arte. Desse modo, ele busca responder à questão "O que é arte?" com uma definição real de arte e não nominal. ${ }^{6}$

Ao responder à questão "O que é arte?", Beardsley não pretende apenas analisar o significado da palavra "arte" e como ela se aplica à classe de coisas à qual se refere. Segundo Beardsley, embora seja um mérito que uma definição consiga corresponder razoavelmente a pelo menos um uso difundido do termo "arte", isso não finda a questão da definição de arte. O termo "arte" é muitas vezes usado para designar uma habilidade específica, de modo que podemos falar de uma arte da medicina, da arte da guerra, da arte de cozinhar, e assim por diante. Esse uso tem sua importância, mas não é aquele com o qual a filosofia lida. Há o sentido mais específico de arte, aquele que nos faz distinguir o tipo de atividade que resulta em pinturas a óleo, composições musicais, livros de literatura, peças de teatro, entre outros. É esse sentido mais restrito do conceito de arte, que uma definição deve capturar. A preocupação de Beardsley (ibid.: 56) é que algum conceito ao menos nos mostre como reunir na mesma classe de coisas um grande número de pinturas, obras literárias, composições musicais e performances.

Beardsley (ibid.: 58) apresenta a seguinte definição de arte: "[u]ma obra de arte é algo produzido com a intenção de conferirlhe a capacidade de satisfazer o interesse estético".

Para compreendermos qualquer cultura é fundamental uma compreensão das várias formas de atividades que nela se manifestam, de acordo com Beardsley (1983: 56). Ele nota que em poucas sociedades não poderíamos identificar atividades artísticas por meio de objetos e eventos que se destacam nestas sociedades. Parece haver uma dimensão da cultura que atravessa as mais variadas sociedades, cuja natureza é o que se pretende articular e, se possível, definir. Para darmos uma definição satisfatória de obra de arte, Beardsley sugere que precisamos fazer referência a algum

6 Uma antiga distinção feita por Aristóteles, retomada pelos filósofos medievais e depois por John Locke. Grosso modo, uma definição nominal é aquela em que o definiendum (o que se quer definir) é um termo (nome); ela especifica o significado do termo. Já uma definição real é aquela em que o definiendum é a coisa designada pelo termo. 
tipo de atividade artística, seja ela a de criação ou de recepção da obra de arte. Se sabemos quais são as obras de arte em uma sociedade (casos já reconhecidos) podemos identificar e analisar quais atividades artísticas envolvem interação com as obras e a função que elas cumprem nesta sociedade. Duas atividades parecem ser centrais para definir obra de arte: a produção e a recepção.

O termo "produção", segundo Beardsley (ibid.: 57), pode ser utilizado de forma ampla, no sentido de fazer, alterar, montar, juntar, organizar. Mas, para que a produção de arte possa se distinguir de uma produção geral, um certo tipo de intenção, a saber, uma intenção estética, deve estar presente. Isso não significa que objetos não possam ser feitos com mais de uma intenção, por exemplo, ao mesmo tempo com uma intenção artística e religiosa ou política. As intenções podem ser variadas, assim como a intenção de satisfazer um interesse estético pode não ser a única, nem a primeira ou a principal intenção. Contudo, a intenção estética deve existir para que algo possa ser classificado como uma obra de arte, de acordo com Beardsley (ibid.: 59).

O termo "intenção" é usado por Beardsley (ibid.: 59) para se referir a uma combinação de desejo e crença. A intenção de produzir uma obra capaz de satisfazer o interesse estético envolve tanto um desejo de produzir tal obra quanto uma crença de que o produto será aquilo que ele pretende. Normalmente, o artista tem um propósito, algo que ele intenciona fazer quando produz obras. O resultado da atividade artística de produção de obras de arte é quase sempre algo (um objeto ou evento) físico ou perceptual. Muitas vezes o que é produzido pode não ter características físicas e perceptuais, pode ser um significado ou uma mensagem, de acordo com Beardsley (ibid.: 57). Desse modo, um caso de arte conceitual ${ }^{7}$ não deixa de ser um produto intencional.

A atividade artística de recepção de obras de arte, para Beardsley (ibid.: 58), compreende uma variedade de atividades realizadas quando interagimos com elas, de forma presencial ou em memória. Ações como ver, ouvir, contemplar, apreender, assistir, ler, pensar, etc. são recepções quando interagem com literatura, música, apresentações, performances, filmes, pinturas, esculturas, entre outras. Segundo Beardsley, temos um

7 O artista Sol LeWitt foi o primeiro a usar a expressão "arte conceitual” em 1967. Ele defendeu que "[n]a Arte Conceitual, a ideia de conceito é o aspecto mais importante da obra". Anteriormente, o termo "arte conceito" foi utilizado em 1961 pela primeira vez por Henry Flynt, músico e escritor, para se referir às atividades do grupo Fluxus em Nova Iorque. Cf. Wood (2002). 
interesse estético na recepção de obras de arte, que é um interesse por obter experiências estéticas.

Beardsley (1982a) defende uma noção ampla de experiência estética. Ele apresenta cinco critérios para qualificarmos uma experiência como estética. Os critérios são: (1) orientação para o objeto (object directedness). "[u]ma orientação voluntariamente aceita da sucessão dos próprios estados mentais"; (2) liberdade sentida (felt freedom), "[u]m sentido de libertação do domínio de algumas preocupações"; (3) afeto desinteressado (detached affect), "[u]m sentido de que os objetos em que o interesse está concentrado são postos um pouco à distância emocionalmente"; (4) descoberta ativa (active discovery), "um estado de destravamento que leva à alegria de ver conexões entre percepções e significados"; (5) totalidade (wholeness), "[u] m sentimento de integração como pessoa" (Beardsley, 1982a: 288289). Beardsley afirma que apenas o primeiro critério é uma condição necessária e que de forma conjunta com três ou mais critérios seria suficiente para definirmos uma experiência estética. Assim, uma experiência estética satisfaz o primeiro critério e satisfaz ao menos três dos demais critérios.

De acordo com Beardsley, temos um interesse estético quando vamos ver uma peça de teatro, assistir a uma apresentação musical, ou ver uma exposição de artes plásticas porque esperamos obter uma experiência estética destas obras quando interagimos com elas. Além disso, esse interesse estético é um interesse por algo ao qual damos valor. Esse valor está relacionado com a experiência estética que obtemos de obras de arte. Normalmente, damos maior valor às obras que são mais capazes de produzir em nós experiências estéticas. Para Beardsley (ibid.: 58), a experiência estética "é desejável, tem valor, satisfaz um interesse humano genuíno". Sem dúvida, esse interesse estético também pode existir perante coisas da natureza. No entanto, a intenção de satisfazer um interesse estético presente na atividade de criação das obras de arte é o que permite distinguir os objetos ou eventos artísticos daqueles da natureza.

\section{Algumas consequências da definição antecipadas por Beardsley}

Beardsley (ibid.: 6062) antecipa algumas consequências da definição estética e as discute em defesa de sua proposta. Segundo a definição estética de Beardsley (ibid.: 60), crianças de sete anos que nada sabem acerca das tradições artísticas ou teorias da arte seriam capazes de produzir obras de arte. Beardsley pensa que isso é correto, se elas possuem uma intenção estética apropriada. Ele considera que não podemos negar que quando uma 
criança escreve um poema, desenha uma figura ou faz uma música, ela produz arte. O ponto básico para tal afirmação é o de que a criança produz algo que considera "esteticamente desfrutável" (aesthetically enjoyable) e a apresenta às pessoas para apreciação.

Outra consequência da definição estética de Beardsley é que ela permite que falsificações de obras de arte possam ser obras de arte. Para Beardsley (ibid.: 61) a questão depende inteiramente da presença de uma intenção estética. Se o falsificador tiver, entre suas intenções, a intenção de gerar interesse estético, conforme a definição estética de arte, ele produz uma obra de arte. De acordo com Beardsley, a intenção de enganar alguém pode não retirar do produto o seu caráter de obra de arte. É claro que, ele não leva em consideração uma história da arte desse tipo de produção, uma vez que esses seriam casos raros.

Uma questão que alguém poderia alegar ser uma consequência da definição estética é a de que, se a intenção é o que conta na produção de arte, ninguém poderia fracassar em produzir uma obra de arte quando tem uma intenção estética. Porém, neste caso o que a teoria defende é que a intenção estética é a intenção de produzir algo para satisfazer um interesse estético e não a intenção de produzir obras de arte. De acordo com a proposta de Beardsley, somente a intenção de criar uma obra de arte não poderia criar uma obra de arte.

Uma obra de arte não pode ser produzida sem qualquer intenção, e, nesse sentido, não pode haver obras de arte não intencionais. Podem ocorrer acidentes no processo do fazer artístico, como uma tinta que escorreu em uma pintura, ou uma rachadura em uma cerâmica, e estes acidentes podem satisfazer um interesse estético. Mas por si só estes acidentes, não intencionais, não poderiam fazer de algo uma obra de arte. Se o artista tem a intenção de produzir algo capaz de conferir a alguém uma experiência estética e se esta é a condição para que o resultado de seu trabalho seja uma obra de arte, o que ele produz com esta intenção é arte. (Beardsley, ibid.: 62).

Finalmente, é uma consequência da definição estética de Beardsley (ibid.: 62) que objetos de mau gosto e sem valor possam ser classificados como obras de arte. Isso ocorre porque a classificação de algo como arte não implica em uma classificação valorativa, entre obras boas e ruins. Uma obra de arte feita com a intenção de satisfazer um interesse estético pode não satisfazer um interesse estético ou satisfazêlo em grau muito baixo. A definição permite que possamos ter um critério para avaliação da arte de acordo com o grau de satisfação de interesse estético que ela possa prover, mas seu uso classificatório independe de um uso valorativo. 


\section{Objeções de Noël Carroll à definição estética de arte}

Para Noël Carroll (1999), a definição apresentada por Beardsley pode negar que objetos e eventos são arte alegando que não foram feitos com a intenção de gerar experiências estéticas. Para tal, bastaria que os defensores da teoria se certificassem de que os artistas não tiveram o desejo e crença indispensáveis para este tipo de intenção. E, além disso, que elementos da sua obra demonstram que esta intenção não esteve envolvida em sua criação.

Por exemplo, o Poème Symphonique para Cem Metrônomos (1962) do compositor húngaro Gyögy Ligeti. A peça é composta por dez artistas performers, em que cada um deles ativa dez metrônomos simultaneamente, que batem descompassadamente até o último deles parar. A recepção da primeira apresentação da peça foi bastante polêmica, o que ocasionou o cancelamento das apresentações seguintes. Segundo o compositor Ligeti (apud Nordwall, 1971: 78), seu trabalho é uma crítica à situação musical contemporânea e "um tipo especial de crítica, uma vez que a própria crítica resulta de meios musicais. (...) e é certo que é bastante irônico".

De acordo com Carroll $(1999,187)$, não devemos atribuir a Ligeti a intenção de fornecer por meio do Poème Symphonique uma experiência estética. No entanto, esta avaliação levaria a negação de Poème Symphonique como uma obra de arte, segundo a interpretação de Carroll da definição estética de Beardsley. E de mesmo modo, segundo Carroll, a definição estética da arte pode excluir outras obras da classificação de obra de arte, como por exemplo, os readymades de Duchamp. Poderia se argumentar, de acordo com a definição estética da arte, que Duchamp claramente não intencionava proporcionar uma experiência estética e que, consequentemente, a Fonte não é uma obra de arte genuína. Carroll conclui que a definição estética, ao contrário de ampla, é na verdade muito restrita porque pode excluir muitas obras de arte de importância já reconhecida.

Além da componente intencional, a definição estética também possui uma componente funcional, segundo Carroll (1999: 188). A intenção de que a obra tenha a capacidade de proporcionar uma experiência estética é concebida em termos de uma função, isto é, a função de proporcionar experiências estéticas. Contudo, para Carroll, além de algumas obras de arte não serem feitas com a intenção de proporcionar experiências estéticas, elas também não possuem a capacidade de proporcionar experiências estéticas. Carroll (1999: 203) conclui que, "[a] capacidade de proporcionar uma experiência estética não é condição necessária para a arte”. 
Além disso, a Fonte de Duchamp seria um exemplo de arte paradigmática, baseada em ideias e não em experiências. A ideia de se fazer uma crítica ao que era ou não aceite como arte pela crítica de arte parece ser mais central na obra de Duchamp que as qualidades estéticas de um mictório. A Fonte pode gerar uma satisfação ao pensarmos nela e, neste caso, até mesmo sem termos um contato físico com a obra, sem a experienciarmos. Segundo o filósofo a obra não foi criada para que suas formas e propriedades perceptuais tivessem a capacidade de proporcionar uma experiência estética. E algumas obras, como por exemplo as de Duchamp, não são procuradas pelo público para a obtenção de experiências estéticas.

O problema geral da definição estética, segundo Carroll, seria o de conferir ao estatuto da arte a função de proporcionar experiências estéticas. Assim um candidato a condição de ter ou não a capacidade de prover uma experiência estética, depende da condição de ser ou não uma obra de arte. Carroll exemplifica a questão com a obra batizada de Paris Air, que em 1919 Duchamp apresentou em Paris. A obra, um frasco cheio de ar parisiense, para Carroll é uma obra travessa (impish). Segundo Carroll (1999: 203), Duchamp não pretendia proporcionar e nem proporcionaria uma experiência estética com a obra em questão. $O$ fato de o frasco ser uma obra de arte é o que nos permite apreciar seu caráter travesso (impishness). Ou seja, o estatuto de obra de arte é que permite considerála travessa. Se este estatuto que permite a experiência estética é definido em termos de se gerar uma experiência estética, temos uma circularidade, de acordo com Carroll.

Carroll (1999: 204) alega que contraexemplos à hipótese da intencionalidade do artista em proporcionar uma experiência estética estão presentes em muitas obras de arte contemporâneas, obras que ele chama de "antiestéticas". Carroll conclui que devemos esperar uma definição que acompanhe as práticas de classificação da arte. Neste sentido, a arte antiestética já existe há algum tempo, não sendo um movimento marginal no século XX, e "tem sido classificada como arte pelos historiadores de arte, críticos, colecionadores e uma grande parte do público informado" (Carroll, 1999: 204). Portanto, uma definição de arte não poderia deixálas de fora.

\section{Como pode Beardsley responder às objeções?}

Sobre a objeção da ausência de intenções estéticas, Beardsley (ibid.: 59) reconhece que as intenções são difíceis de serem conhecidas por serem 
privadas. Mesmo assim, ele fornece duas respostas à Carroll. Primeiro, as intenções entendidas como os "motivos", segundo Beardsley, são aquilo com o qual os historiadores trabalham. Elas fornecem explicações da razão pela qual pessoas fizeram o que fizeram. Pois, o historiador está envolvido com as intenções da criação de uma obra de arte, quando percebe desenvolvimentos estilísticos e inovações em obras de arte (Beardsley, 1982b: 305). Como observou o historiador Erwin Panofsky (apud Beardsley, 1982b: 305), há sinais simples de intenções do artista no próprio objeto. De modo que, "podemos discernir no tema de uma pintura de Rubens, que se pretendia representar vividamente um martírio particular" e, de mesmo modo, "podemos discernir em sua composição e harmonias de cores que alguém deveria estar interessado em darlhe qualidades estéticas emotivas" (Beardsley, 1982b: 305).

Segundo, Beardsley (1982b: 306) nota que é possível tratar um objeto como arte mesmo sem observarmos as fontes de intenções estéticas em um objeto. Ele se refere às muitas obras de arte que pertencem à classe ou gêneros que são chamados ou reconhecidos como esculturas, desenhos, gravuras, iluminação de manuscritos, abstrações hardedge ${ }^{8}$, entre outros. Beardsley chama estas classes de "tipos de arte" (artkinds). Para ele, o que estabelece um tipo de arte é que suas instâncias individuais são criadas com a intenção de proporcionar uma experiência estética. A intenção deve estar presente, mas, uma vez que, um tipo de arte consegue ser socialmente estabelecido, seu rótulo é estendido aos novos exemplos dele. Se um historiador ou arqueólogo da arte descobre uma escultura Minoica (ou uma estátua de Buda), mesmo que não saiba as intenções reais de seu criador, ele pode tratar o objeto como obra de arte por considerálo da classe ou gênero de esculturas.

Algo pode ter sido feito com a intenção de ter a capacidade de proporcionar uma experiência estética e não ter essa capacidade. No entanto, se a intenção do artista é a de satisfazer um interesse estético, isso não significa que este interesse seja satisfeito, ou ao menos não no grau desejado. Mesmo que o interesse estético intencionado não seja satisfeito como o pretendido, uma atividade pode ser classificada como uma atividade artística, segundo a definição estética de Beardsley. Algo pode ter sido feito com a intenção de proporcionar experiências estéticas e falhar. Ter ou não a capacidade de proporcionar experiências estéticas não envolve a

8 O termo "HardEdge" se refere a um tipo de pintura abstrata com formas e contornos delimitados, um tipo menos gestual que o Expressionismo Abstrato norteamericano. 
definição de arte e sim a avaliação da arte. Se uma definição funcionalista da arte como a de Beardsley for correta, é possível avaliar uma obra de arte pela sua capacidade de proporcionar um grau mais elevado de experiência estética do que outras, permitindo assim um critério para atribuir maior ou menor valor às obras de arte.

Segundo Carroll, a partir do exemplo Paris Air de Duchamp, a condição de ter ou não a capacidade de proporcionar uma experiência estética depende da condição de ser ou não uma obra de arte. Assim, se o estatuto que permite a experiência estética é definido em termos de gerar uma experiência estética, temos uma circularidade. ${ }^{9}$ Entretanto, podemos entender que esta objeção se aplica somente a um certo grupo de propostas, a saber, aquelas que propõem - diferentemente de Beardsley - que as propriedades estéticas de um objeto ou a experiência estética por ele ocasionada são dependentes de que ele seja primeiro classificado como arte. A objeção é condicionada à aceitação das teorias que defendem que o estatuto de arte de algo advém de uma atribuição. Por esse motivo, ela não recai sobre a definição estética de arte de Beardsley.

Carroll afirma que a Fonte seria um exemplo de obra de arte paradigmática baseada em ideias e não em experiências. Entretanto, podemos notar que Carroll se refere à experiência estética como algo ligado somente à percepção. E quando analisamos as características da noção de experiência estética proposta por Beardsley, notamos que ele a concebe de forma mais ampla que a percepção de propriedades estéticas. Carroll alega que algumas obras de arte, que ele chama de "antiestéticas", não possuem a capacidade de proporcionar experiências estéticas por não possuírem propriedades estéticas relevantes. Contudo, um interesse estético pode ser satisfeito, mesmo no caso de obras com propriedades estéticas irrelevantes. Isso ocorre porque um interesse estético pode ser satisfeito a partir da compreensão de uma ideia, assim como por meio do cômico ou o irônico, de acordo com Beardsley.

Obras como os readymades de Duchamp têm sido classificadas pelos historiadores, críticos e colecionadores como obras de arte, conforme Carroll aponta. Mas uma definição que as inclua não precisa deixar necessariamente o estético de fora. Mesmo que elas sejam obras baseadas em ideias e não em experiências, como Carroll defende, elas podem gerar outro tipo de experiência que inclua a atenção direcionada ao objeto ou evento, uma capacidade de descoberta, uma sensação de liberdade desconectada de fins práticos, uma experiência de totalidade ou integração.

9 A objeção da circularidade foi inicialmente desenvolvida por Davies (1991). 
Ou seja, uma obra de arte conceitual pode gerar no seu experienciador todas ou algumas das características propostas por Beardsley para descrever a experiência estética.

Por outro lado, Beardsley (ibid.: 60) afirma sobre a Fonte que Duchamp não estabeleceu "um novo significado de 'obras de arte', nem realmente inaugurou uma tradição que levou à aceitação de peças de encanamento (ou outros readymades) como obras de arte”. É mais provável, segundo a visão de Beardsley, que a intenção de Duchamp com a Fonte era a de "provar ao júri que mesmo a sua tolerância tinha limites e que não aceitaria qualquer coisa". ${ }^{10}$ Por essas posições Beardsley é associado à posição que nega os readymades como obras de arte genuínas. No entanto, cabe aqui a ponderação de que Beardsley não é categórico sobre nenhum caso. Há espaço para discussão sobre a distinção entre arte e algum tipo de brincadeira feita por meio da arte, ou crítica, dado que, para Beardsley (ibid.: 60), o "prazer da sagacidade pode ser uma experiência estética. Mas o senso comum não deve ser abandonado, juntamente com a perspicácia filosófica nestas matérias".

Classificar algo como obra de arte somente porque faz um comentário crítico sobre a arte, nos levaria a ter que explicar porque não fazemos o mesmo com artigos de revistas e comentários de jornais sobre a arte. Da mesma forma, classificar algo como obra de arte só porque é exposto para um público não a distinguiria de outros objetos expostos em exposições comerciais, nos museus de ciências naturais, entre outros. $\mathrm{Ou}$ ainda, classificar coisas como obra de arte "só porque são chamadas de arte por aqueles que são chamados de artistas, porque eles fazem coisas que eles chamam de arte", de acordo com Beardsley (ibid.: 60), é recair em circularidade e não classificar. Para o filósofo, é vital preservar a distinção entre os objetos que fazem e aqueles que não fazem parte das atividades artísticas em virtude da sua ligação com o interesse estético, "e nenhuma outra palavra melhor do que 'arte' é tão apropriada para isso" (Beardsley, ibid.: 60).

Beardsley (ibid.: 60) considera que casos como a Fonte de Duchamp e outros casos limítrofes à definição estética da arte ocorrem para a maioria das definições, especialmente as que envolvem atividades e objetos culturais. Se formos caridosos, haverá muitas coisas que a definição estética pode cobrir, mas ela também exclui outras coisas. Uma linha de delimitação mais precisa sobre o que ela inclui e o que ela exclui não é o esperado por

10 A proposta do Salão dos Independentes de Nova Iorque de 1917 era a de que aceitariam qualquer coisa como arte. 
Beardsley de sua definição. Não sabemos exatamente "[q]uão pronunciada deva ser a intenção estética", ou "[q]uanta atividade por parte do artista é requerida para se dizer que ele é um produtor" (Beardsley, ibid.: 60). Há na definição estética, segundo Beardsley, uma certa indeterminação. Mas a definição estética deve ser rejeitada somente se ela não traçar uma linha de distinção útil entre arte e não arte.

De acordo com Richard Wollheim (1980: 148), há uma excessiva influência de Duchamp e seus readymades nas elaborações teóricas sobre arte. Para ele, é uma má compreensão da obra de Duchamp pensar que a existência de readymades exige uma reformulação da teoria estética, de modo a apresentar a Fonte com exemplo essencial de obra de arte. Quando na verdade, uma boa teoria da arte deve preservar "o caráter profundamente ambíguo, altamente provocativo e completamente irônico" da Fonte e outros readymades, ou reconhecêlos como "exemplos especiais, o que eles realmente são" (Wollheim, 1980:148149). Assim, se considerássemos realmente que os readymades fossem o modelo central para a teorização da arte, casos essenciais para teorias da arte, esses casos perderiam aquilo que eles possuem de especial: a crítica e a contestação a um modelo vigente, a uma situação específica nas artes contra qual a crítica se volta. A avantgarde ${ }^{11}$ existe em função da existência de obras que predominantemente são os casos de arte e que dão sentido à crítica que ela faz.

Por fim, a definição estética de Beardsley parece restrita se pensamos em um curto período da história da arte, a do século XX, período analisado por Carroll. Porém, a definição estética é ampla e inclusiva quando pode ser aplicada àquelas produções de antigas sociedades, às sociedades não ocidentais, às primeiras artes - como as pinturas rupestres do Paleolítico ou as construções, esculturas e objetos da Mesopotâmia. Ela pode incluir até mesmo as obras de arte que não se encontram nos museus, por exemplo, a arte de rua como o graffiti, entre outras manifestações. A definição estética de arte permite que possamos olhar como arte os objetos feitos para cumprirem primordialmente funções religiosas ou políticas em uma sociedade, desde que cumpram ao menos uma função estética.

11 Uso o termo avantgarde para me referir tanto às vanguardas artísticas do início do século XX, movimentos como o Dadaísmo e Surrealismo, quanto às expressões da segunda metade do século, como o grupo Fluxus e a Arte Conceitual. 


\section{Considerações finais}

A existência da arte ao longo da história nos faz querer entender qual é o papel que ela tem cumprido, por que a buscamos, por que a produzimos, por que as pessoas têm algum interesse por arte e a preservam. A proposta de Beardsley tenta dar uma resposta a essas questões, para além dos desafios postos pela arte do século XX. Isso não significa que ele não tenha fornecido respostas a esse desafio. Como tentei mostrar neste artigo, Beardsley elabora respostas às principais objeções à definição estética de arte. Se ele não encerra a questão, ao menos nos deixa reflexões acerca do papel da experiência estética na definição de arte a partir das relações de produção e recepção de obras de arte.

As definições estéticas de arte foram muito criticadas durante a segunda metade do século XX. Os seus críticos defenderam que elas deveriam ser abandonadas por não responderem à produção artística do período. Não é uma surpresa que a definição estética de Beardsley tenha gerado tanta controvérsia. Contudo, além de ser a mais importante definição estética de arte do período, ela abre o campo para a retomada da discussão sobre o caráter estético das obras de arte. Debate que ainda está em curso.

\section{Referências Bibliográficas}

Beardsley, Monroe. "Aesthetic Experience". In: The Aesthetic point of view. Ithaca, New York: Cornell University Press, 1982a.

- "Redefining Art". In: The Aesthetic point of view. Ithaca, New York: Cornell University Press, $1982 \mathrm{~b}$.

— "An Aesthetic Definition of Art". In: Lamarque, Peter (Org.). Aesthetics and the Philosophy of Art: The Analytic Tradition. Oxford: Blackwell Publishing, 2005.

Carroll, Noël. (1999). Filosofia da Arte. Tradução Rita Canas Mendes. Lisboa: Edições Texto \& Grafia, 2010. (Coleção: Synopsis Manuais).

- Aesthetics: Philosophical Essays. Cambridge: Cambridge University Press, 2001.

Danto, Arthur. "The artworld". The Journal of Philosophy, v. 61, n 19, out. 1964, pp. 571584.

- The Transfiguration of the Commonplace: A Philosophy of Art. Cambridge: Harvard University Press, 1981.

Davies, Stephen. Definitions of Art. Ithaca and London: Cornell University Press, 1991.

Dickie, George. Art and the Aesthetic: An Institutional Analysis. Ithaca: Cornell University Press, 1974.

— The Art Circle. New York: Haven Publications, 1984. 
Nordwall, Ove. György Ligeti: Eine Monographie. Mainz: Schott, 1971.

Stock, Kathleen. "Definition of Art". In: Davies, Stephen, et al. (Ed.) Blackwell Companion to Aesthetics. $2^{\mathrm{a}}$ edição. Oxford: WileyBlackwell, 2010, pp. 231234.

Wimsatt, William.; Beardsley, Monroe. (1949). "The Intentional Fallacy". In: Lodge, David (ed.). 20th Century Literary Criticism: A Reader. London: Longman, 1972.

Wollheim, Richard. (1980). A Arte e Seus Objetos. Tradução Marcello Brandão Cipolla. São Paulo: Martins Fontes, 2015.

Wood, Paul. Arte conceitual. Tradução Bertina Bischof. São Paulo: Cosac Naify, 2002.

\title{
RESUMO
}

Monroe Beardsley apresenta uma definição estética de arte em "An Aesthetic Definition of Art" (1983), defendendo a ligação necessária entre arte e estética. Beardsley propõe que uma obra de arte é algo feito com a intenção de ter a capacidade de satisfazer um interesse estético. Noël Carroll alega que existem obras de arte criadas sem intenções estéticas e que algumas obras não possuem a capacidade de proporcionar experiências estéticas. Além disso, Carroll argumenta que existem obras cujo estatuto de arte é anterior à apreciação destas obras como arte. Este artigo pretende apresentar a definição estética de arte de Beardsley e analisar como as objeções a ela podem ser respondidas.

Palavraschave: Estética - Noël Carroll - Monroe Beardsley - definição de arte - experiência estética

\begin{abstract}
Monroe Beardsley presents an aesthetic definition of art in "An Aesthetic Definition of Art" (1983), in which he claims that there is a necessary connection between art and aesthetics. Beardsley proposes that a work of art is something made with the intention of having the capacity to satisfy an aesthetic interest. Noël Carroll claims that there are artworks created without aesthetic intentions and that some artworks do not have the capacity to provide aesthetic experiences. In addition, Carroll argues that there are artworks whose status of art is prior to the appreciation of these works as art. The aim of this paper is to present Beardsley's aesthetic definition of art and analyze how objections to it can be answered.
\end{abstract}

Keywords: Aesthetics - Noël Carroll - Monroe Beardsley - definition of art aesthetic experience 